\title{
Atividade antimicrobiana de extratos hidroalcoólicos de Lafoensia pacari A. St.-Hil., Lythraceae, frente a bactérias multirresistentes de origem hospitalar
}

\author{
Zenaldo Porfirio, ${ }^{* 1}$ Gildo C. Melo-Filho, ${ }^{2}$ Valter Alvino, ${ }^{3}$ Maria Raquel F. Lima, ${ }^{4}$ \\ Antônio E.G. Sant'Ana ${ }^{5}$ \\ ${ }^{1}$ Laboratório de Microbiologia, Universidade Estadual de Ciências da Saúde de Alagoas Campus Governador \\ Lamenha Filho. Rua Dr. Jorge de Lima 113, Trapiche da Barra, 57010-382 Maceió-AL, Brasil \\ Universidade Federal de Alagoas, Campus A. C. Simões, Av. Lourival Melo Mota s/n, \\ Tabuleiro do Martins, 57072-970 Maceió-AL, Brasil \\ ${ }^{2}$ Universidade Estadual de Ciências da Saúde de Alagoas, Universidade Estadual de Ciências da Saúde de \\ Alagoas Campus Governador Lamenha Filho. Rua Dr. Jorge de Lima 113, Trapiche da Barra, \\ 57010-382 Maceió-AL, Brasil \\ ${ }^{3}$ Escola de Enfermagem e Farmácia, Universidade Federal de Alagoas, Campus A. C. Simões, \\ Av. Lourival Melo Mota s/n, Tabuleiro do Martins, 57072-970 Maceió-AL, Brasil \\ ${ }^{4}$ Instituto de Química e Biotecnologia, Departamento de Química, Universidade Federal de Alagoas, \\ Campus A. C. Simões, Av. Lourival Melo Mota s/n, Tabuleiro do Martins, 57072-970 Maceió-AL, Brasil \\ ${ }^{5}$ Laboratório de Produtos Naturais, Instituto de Química, Universidade Federal de Alagoas, Campus A. C. Simões, \\ Av. Lourival Melo Mota s/n, Tabuleiro do Martins, 57072-970 Maceió-AL, Brasil.
}

\begin{abstract}
RESUMO: Os microrganismos patogênicos multirresistentes apresentam-se como grandes responsáveis por milhões de mortes em todo o mundo, principalmente Pseudomonas aeruginosa e Staphylococcus aureus, responsáveis por grande parte das infecções hospitalares. A preocupação com estas espécies faz com que novas pesquisas busquem alternativas para controlar estes microrganismos de uma forma mais eficiente e também mais econômica. Os extratos fitoterápicos são alternativas promissoras para este fim, visto que são uma imensa fonte de compostos de ação biológica. O objetivo do trabalho foi a elucidação da atividade antimicrobiana do extrato de Lafoensia pacari A. St.-Hil., Lythraceae, frente a linhagens de bactérias multirresistentes ( $P$. aeruginosa, S. aureus) isoladas de pacientes com múltiplas infecções internados na Unidade de Emergência de Maceió. Os testes de atividade antibacteriana foram avaliados pelo método de difusão em meio sólido (Kirby-Bauer) modificado. De acordo com os ensaios in vitro, foi constatado que $96,4 \%$ das linhagens de bactérias utilizadas na pesquisa apresentaram-se sensíveis ao extrato da folha da planta, demonstrando atividade antibacteriana. Halos de inibição de crescimento de até $26 \mathrm{~mm}$ foram encontrados. Dessa forma, conclui-se que o extrato de Lafoensia pacari apresenta possibilidades de se encontrar substâncias úteis no combate a bactérias multirresistentes.
\end{abstract}

Unitermos: Infecção hospitalar, bactérias multirresistentes, Lafoensia pacari, Lythraceae.

\begin{abstract}
Antibacterial activity of the hydro-alcoholic extracts of Lafoensia pacari Saint Hil. against multiresistant bacterial strains from hospital source". Multiresistant pathogenic microorganisms are responsible for million of death all the world, mainly Pseudomonas aeruginosa and Staphylococcus aureus that are responsible for great part of hospital infections. The concern with this species does new researches to find out alternatives to control these microorganisms in the way more efficient and more economic. The phytoterapic extracts are promissory alternatives for that purpose because they are an immense source of biological action. The objective of this study was to evaluate the antimicrobial activity of Lafoensia pacari A. St.-Hil., Lythraceae, extract on multiresistant bacterial strains ( $P$. aeruginosa, $S$. aureus) that have been isolated from patients with multiple infections occupying an Emergency Unit from Maceió in Brazil. The antibacterial activity experiments were evaluated by agar diffusion tests. Agreeable us experiments in vitro, ascertain that $96,4 \%$ of bacterial strains utilized in this research have showed susceptible to the plant's leaf extract, it means an excellent antibacterial activity. Halos of bacterial inhibition until $26 \mathrm{~mm}$ were observed. Thus, it can be concluded that the Lafoensia pacari extract has showed as an excellent product to combat multiresistant bacterial.
\end{abstract}

Keywords: Hospital infection, multiresistant bacterial, Lafoensia pacari, Lythraceae. 


\section{INTRODUÇ̃̃O}

As bactérias tidas como grandes causadoras de infecções hospitalares têm ganhado grande importância para a Organização Mundial de Saúde, visto que o tratamento de patologias causadas por estes microrganismos está cada vez mais difícil devido ao aparecimento de resistência aos fármacos de última geração (Coelho et al., 1994). As bactérias Pseudomonas aeruginosa, Staphylococcus aureus, Klebsiella pneumoniae, Enterobacter sp., Acinetobacter sp. e Enterococcus faecalis são as principais espécies que vêm desenvolvendo um alto grau de resistência a antibióticos (Horan et al., 1986). Como o mecanismo de resistência microbiana à droga varia de microrganismo para microrganismo e de droga para droga (Schaberg et al., 1991), o tempo necessário para adquirir a multirresistência será bastante variável.

Os microrganismos que têm apresentado um interesse maior nos processos infecciosos humanos são: Staphylococcus aureus, Pseudomonas aeruginosa, Klebsiella pneumoniae, Escherichia coli e Enterococcus faecalis. Estas bactérias causam inúmeras infecções, tais como: endocardite bacteriana aguda, infecções respiratórias, bacteremia, sepcemia, osteomielite aguda e crônica, piomiosite aguda purulenta, abcesso cerebral, infecções de próteses articulares, do trato urinário (Garibaldi, 1992), de sítio cirúrgico, além de causarem surtos hospitalares de infecção (Jawetz et al., 2002).

O conhecimento histórico do uso de plantas medicinais nos mostra ao longo da história da humanidade que, pela própria necessidade do homem, elas foram um dos primeiros recursos terapêuticos disponíveis, inclusive sendo utilizadas na arte de embalsamar cadáveres pelos antigos egípcios (Fluit et al., 2000). Tais plantas constituem uma imensa fonte de compostos de ampla atividade biológica e a utilização delas, principalmente no tratamento de doenças infecciosas, representa uma grande contribuição para a descoberta de novos agentes terapêuticos no combate de microrganismos multirresistentes (Oliveira et al., 2002).

A Lafoensia pacari A. St.-Hil. é uma planta pertencente à família Lythraceae, subclasse Rosidae e ordem Myrtales. O gênero Lafoensia esta amplamente distribuído nas regiões tropicais e subtropicais e dentre seus principais compostos químicos estão polifenóis, taninos, quinonas e principalmente alcalóides. Possui vários nomes vulgares, entre eles: pacari, louro-de-serra (Santa Catarina), dedaleira-amarela, mangabeira-brava (Mato Grosso), copinho, dedal, dedaleiro (São Paulo), entre outros. Na medicina popular, a raiz é tônica e febrífuga (Correia, 1984; Lorenzi, 1992; Reitz, 1969).

O presente trabalho teve como objetivo avaliar a atividade antimicrobiana do extrato hidro-alcoólico obtido das folhas e da casca do caule de Lafoensia pacari frente a cepas de bactérias multirresistentes.

\section{MATERIAL E MÉTODOS}

\section{Amostras microbianas}

As linhagens bacterianas usadas nos experimentos foram cedidas pelo Laboratório de Patologia Clínica da Santa Casa de Misericórdia de Maceió. Foram escolhidas para o trabalho 24 linhagens de Pseudomonas aeruginosa (Gram negativa), doze de Staphylococcus aureus (Gram positiva), seis de Klebsiella pneumoniae (Gram negativa), num total de 42 linhagens bacterianas, todas resistentes a pelo menos três fármacos pertencentes a diferentes classes de antimicrobianos (quinolonas, cefalosporinas, aminoglicosídeos e penicilinas), classificando-as como bactérias multirresistentes. Foram utilizadas cepas de Pseudomona aeruginosa ATCC 2785, Staphylococcus aureus ATCC 25923 e K. pneumoniae ATCC 13883 que são cepas com perfil de resistência padronizada internacionalmente, totalizando 45 linhagens bacterianas.

\section{Extratos vegetais}

Os extratos foram obtidos no Laboratório de Pesquisa em Recursos Naturais do Departamento de Química da UFAL. Foram produzidos dois extratos, um a partir da casca do caule e outro a partir das folhas da L. pacari. A Lafoensia pacari St. Hil foi coletada pelo professor Dr. José Elias de Paula, em Brasília em 1999 e a exsicata encontra-se depositado no herbário da UNB No. JEP 3535.

\section{Preparo dos extratos para realização dos testes}

Cada extrato $(200 \mathrm{mg})$ foi solubilizado em $1 \mathrm{~mL}$ de água-metanol a 33\% e dissolvidos com o auxílio de um sonicador (ultrassom) e adição de $40 \mu \mathrm{L}$ de dimetilsulfóxido (DMSO).

\section{Preparo dos meios de cultura e esterilização}

Os meios de cultura BHI (Brain Heart Infusion - Difco, Brasil), Agar Müeller-Hinton (Difco, Brasil) e Ágar-Ágar (Difco, Brasil), foram preparados de acordo com as recomendações do fabricante. Os meios foram esterilizados em autoclave (calor úmido), à temperatura de $121{ }^{\circ} \mathrm{C}$, durante $15 \mathrm{~min}$, em vapor constante.

\section{Testes de sensibilidade e resistência das linhagens microbianas}

O método utilizado foi o de difusão em Ágar, onde foram produzidos pequenos poços no meio de cultura com capacidade para $50 \mu \mathrm{L}$. Para isso, ponteiras estéreis foram colocadas em pé sobre uma fina camada de ágar-ágar em placa de Petri. Em seguida, $1 \mathrm{~mL}$ de meio caldo nutriente contendo aproximadamente $10^{6}$ bactérias foi adicionado 
em tubo contendo $13 \mathrm{~mL}$ de meio Agar Müeller-Hinton liquefeito a temperatura de $45^{\circ} \mathrm{C}$. A mistura foi vertida na placa que continha as ponteiras. Após $10 \mathrm{~min}$ as ponteiras foram retiradas formando os poços. Em cada um foi pipetado $40 \mu \mathrm{L}$ ( $8 \mathrm{mg}$ ) de extrato a ser analisado e no poço central, o controle (água-metanol a 33\%). As placas foram mantidas em estufa bacteriológica aquecida a $37^{\circ} \mathrm{C}$ durante $24 \mathrm{~h}$ e a determinação da atividade antimicrobiana foi medida de acordo com o halo de inibição do crescimento bacteriano em volta dos poços. As zonas de inibição foram mensuradas com um halômetro em mm.

\section{Teste da concentração mínima inibitória (CMI)}

Para a determinação deste, foram selecionadas seis espécimes bacterianas, duas de cada espécie, sendo uma dessas pertencente à cepa padrão. As concentrações utilizadas para essa determinação foram de 32,5; 62,5; 125 e $250 \mu \mathrm{g}$ de extrato da planta diluído para $1 \mathrm{~mL}$ de meio líquido BHI, aos quais foram repicadas as cepas bacterianas. Esses tubos foram acondicionados em estufa bacteriológica em temperatura de $37^{\circ} \mathrm{C}$ por 24 h. Para averiguação dos resultados foi semeado $10 \mu \mathrm{L}$ de cada solução em placas contendo o meio de cultura Ágar Müeller-Hinton e novamente mantido em estufa bacteriológica sob as mesmas condições. Os resultados foram determinados de acordo com o aparecimento ou não de colônias bacterianas na superfície do meio de cultura.

\section{RESULTADOS}

Dentre as 45 linhagens testadas, o extrato de folhas de L. pacari demonstrou atividade bactericida em 42 delas, o que representa uma efetividade de 93,33\%. Somente três linhagens de Pseudomonas aeruginosa não apresentaram sensibilidade a este extrato (Tabela 1). Todas as outras linhagens, incluindo as de diferentes espécies $(S$. aureus e K. pneumoniae) tiveram seu crescimento inibido por este extrato na concentração de $8 \mathrm{mg} / 40 \mu \mathrm{L}$ usada nos testes, inclusive as linhagens padrão (Tabela 1).

O extrato da casca do caule de L. pacari também foi testado em 45 linhagens e teve eficiência de 86,66\% no total. Porém, houve um perfil de resistência de $25 \%$ frente as Pseudomonas aeruginosa multirresistentes (Tabela 2), três dentre essas, também foram resistentes ao extrato de folhas de $L$. pacari. Quanto aos resultados com $K$. pneumoniae e $S$. aureus valores semelhantes foram observados em ambos os extratos (Tabela 1 e 2).

De acordo com a Figura 1, podemos observar que não houve inibição do crescimento bacteriano quando usado os controles com o diluente (água-metanol 33\%) e sem adição de qualquer substância todavia, foi evidenciado ação nos testes com o extrato da casca do caule contra a bactéria Staphylococcus aureus. Desta forma confirmamos a atividade bactericida dos extratos da casca do caule da Lafoensia pacari com as diferentes linhagens bacterianas de acordo com os experimentos realizados (Figura 1).

Nos testes de concentração mínima inibitória (CMI) foram observados os seguintes resultados. Nas concentrações de 32,5 e $62,5 \mu \mathrm{g} / \mathrm{mL}$ o extrato de folhas não inibiu o crescimento de nenhuma das seis bactérias; na concentração de $125 \mu \mathrm{g} / \mathrm{mL}$, o extrato promoveu uma inibição parcial do crescimento das linhagens de $P$. aeruginosa e inibiu totalmente o crescimento de todas as linhagens de S. aureus e K. pneumoniae; na concentração de $250 \mu \mathrm{g} / \mathrm{mL}$, a inibição de crescimento foi total em todas as linhagens analisadas (Figura 2).

Resultados menos expressivos foram obtidos com o extrato produzido a partir da casca do caule da $L$. pacari. Nas concentrações de 32,5 e $62,5 \mu \mathrm{g} / \mathrm{mL}$, o extrato também não inibiu o crescimento de nenhuma cepa bacteriana. A $125 \mu \mathrm{g} / \mathrm{mL}$, houve inibição do desenvolvimento das linhagens de $S$. aureus e de uma cepa de P. aeruginosa. A $250 \mu \mathrm{g} / \mathrm{mL}$, houve inibição do crescimento das três linhagens analisadas (Figura 3).

Tabela 1. Perfil de sensibilidade bacteriana in vitro ao extrato hidro-alcoólico de folhas L. pacari, na concentração de $8 \mathrm{mg} / 40 \mu \mathrm{L}$.

\begin{tabular}{|c|c|c|c|c|c|}
\hline Microrganismos & $\begin{array}{c}\text { Número de } \\
\text { linhagens testadas }\end{array}$ & $\begin{array}{c}\text { Total de linhagens } \\
\text { sensíveis }\end{array}$ & $\begin{array}{c}\text { Sensibilidade em } \\
\%\end{array}$ & $\begin{array}{l}\text { Total de linhagens } \\
\text { resistentes }\end{array}$ & Resistência em \% \\
\hline P. aeruginosa & 24 & 21 & 87,5 & 3 & 12,5 \\
\hline $\begin{array}{l}\text { P. aeruginosa } \\
\text { ATCC } 27853\end{array}$ & 1 & 1 & 100,0 & 0 & 0,0 \\
\hline S. aureus & 12 & 12 & 100,0 & 0 & 0,0 \\
\hline $\begin{array}{l}\text { S. aureus } \\
\text { ATCC } 25923\end{array}$ & 1 & 1 & 100,0 & 0 & 0,0 \\
\hline K. pneumoniae & 6 & 6 & 100,0 & 0 & 0,0 \\
\hline $\begin{array}{l}\text { K. pneumoniae } \\
\text { ATCC } 13883\end{array}$ & 1 & 1 & 100,0 & 0 & 0,0 \\
\hline Total & 45 & 42 & 93,33 & 3 & 6,67 \\
\hline
\end{tabular}


Tabela 2. Perfil de sensibilidade bacteriana in vitro ao extrato hidro-alcoólico da casca do caule de L. pacari, na concentração de 8 $\mathrm{mg} / 40 \mu \mathrm{L}$.

\begin{tabular}{|c|c|c|c|c|c|}
\hline Microrganismos & $\begin{array}{c}\text { Número de } \\
\text { linhagens testadas }\end{array}$ & $\begin{array}{c}\text { Total de linhagens } \\
\text { sensíveis }\end{array}$ & $\begin{array}{c}\text { Sensibilidade em } \\
\%\end{array}$ & $\begin{array}{l}\text { Total de linhagens } \\
\text { resistentes }\end{array}$ & Resistência em \% \\
\hline P. aeruginosa & 24 & 18 & 75,0 & 6 & 25,0 \\
\hline $\begin{array}{l}\text { P. aeruginosa } \\
\text { ATCC } 27853\end{array}$ & 1 & 1 & 100,0 & 0 & 0,0 \\
\hline S. aureus & 12 & 12 & 100,0 & 0 & 0,0 \\
\hline $\begin{array}{l}\text { S. aureus } \\
\text { ATCC } 25923\end{array}$ & 1 & 1 & 100,0 & 0 & 0,0 \\
\hline K. pneumoniae & 6 & 6 & 100,0 & 0 & 0,0 \\
\hline $\begin{array}{l}\text { K. pneumoniae } \\
\text { ATCC } 13883\end{array}$ & 1 & 1 & 100,0 & 0 & 0,0 \\
\hline Total & 45 & 39 & 86,66 & 6 & 13,34 \\
\hline
\end{tabular}

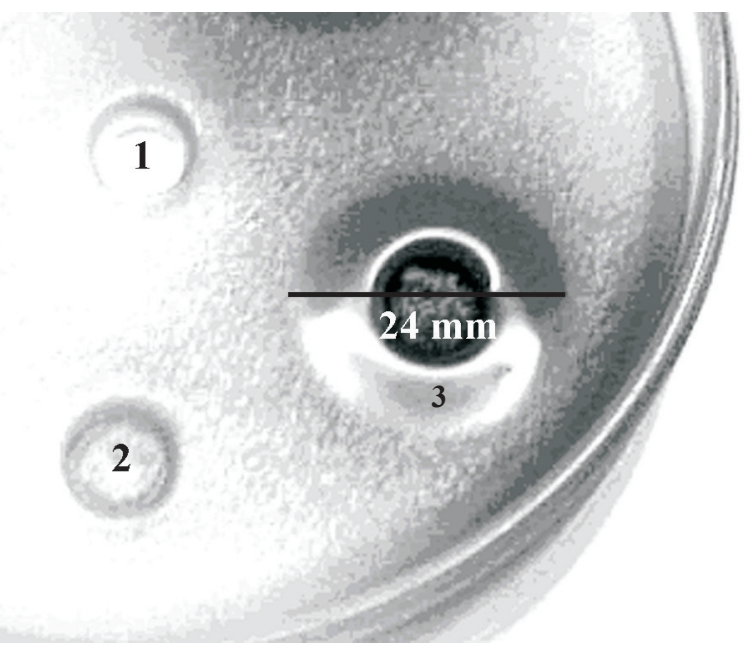

Figura 1. Atividade antimicrobiana do extrato de L. pacari. 1.Ausência de halo no controle negativo (sem adição de substância). 2. Ausência de halo no controle com MeOH 33\%. 3. Halo de inibição de crescimento de Staphylococcus aureus por extrato da casca do caule de L. pacari, medindo $24 \mathrm{~mm}$.

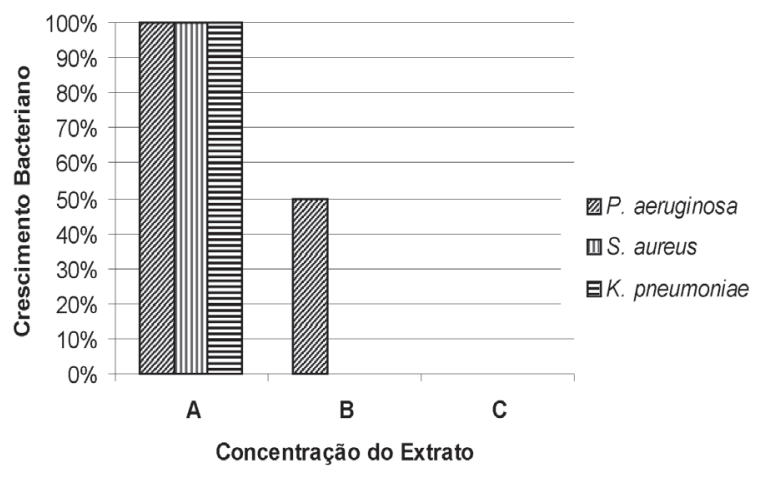

Figura 2. Crescimento bacteriano em função da concentração do extrato de folhas de L. pacari. A. Concentração de $62,5 \mu \mathrm{g} / \mathrm{mL}$; B. concentração de $125 \mu \mathrm{g} / \mathrm{mL}$; C. concentração de $250 \mu \mathrm{g} / \mathrm{mL}$.

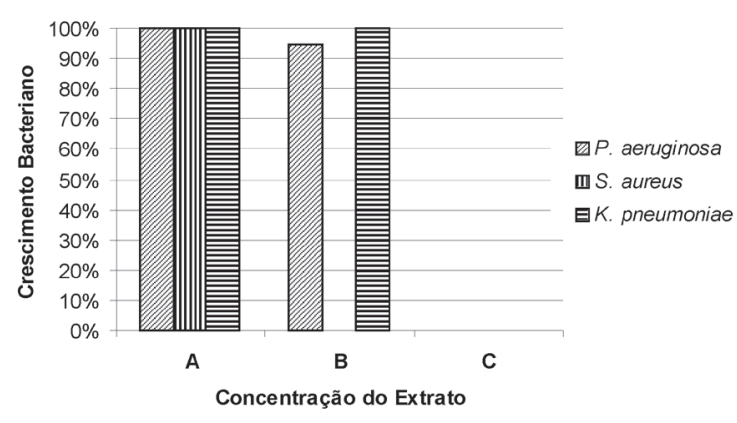

Figura 3. Crescimento bacteriano em função da concentração do extrato da casca do caule de L. pacari. A. concentração de 62,5 $\mu \mathrm{g} / \mathrm{mL}$; B. concentração de $125 \mu \mathrm{g} / \mathrm{mL}$; C. concentração de 250 $\mu \mathrm{g} / \mathrm{mL}$

\section{DISCUSSÃO}

Os resultados obtidos nos experimentos vieram comprovar os resultados encontrados por Alves et al. (2002) num estudo de monitoração biológica de plantas medicinais brasileiras. Em ambos, ficou comprovada a alta ação bactericida dos extratos de L. pacari, tanto em bactérias Gram-positivas quanto em Gram-negativas, assim observado para as cepas de $S$. aureus e $P$. aeruginosa.

A propriedade bactericida dos extratos de $L$. pacari também foi confirmada por Menezes (2002) num estudo feito na Unifesp que usou os extratos de $L$. pacari como alternativa terapêutica para erradicação de Helicobacter pylori, bastonete Gram-negativo associado à gastrite, úlcera e carcinomas gástricos.

Metodologia semelhante foi utilizada nos estudos de concentração mínima inibitória (CMI) feitos por Nascimento (2000) onde os extratos, que em diluições de $200 \mu \mathrm{g} / \mathrm{mL}$ impediram o crescimento das linhagens bacterianas, foram considerados dotados de boa atividade. Salientando-se que neste trabalho as concentrações mínimas inibitórias encontradas para os extratos de $L$. 
pacari foram de no máximo $125 \mu \mathrm{g} / \mathrm{mL}$, o que torna claro $\mathrm{o}$ alto potencial bactericida.

A partir destes resultados podemos concluir que os extratos de Lafoensia pacari possuem atividade antimicrobiana tanto em bactérias Gram-positivas quanto em bactérias Gram-negativas, mostrando que possuem um amplo espectro de ação, neste aspecto comparando-se aos antimicrobianos ceftazidima e ciprofloxacina.

\section{REFERÊNCIAS}

Alves TMA, Silvia AF, Brandão M, Grandi TSM, Smânia EFA, Junior AS, Zani, CL 2000. Brazilian screening of medicinal plants, In <http://www.fiocruz.com.br>, acesso em 7 abr 2003.

Coelho R, Jimenez J, Garcia M 1994. Spective study of infection colonization and carriage of methicillin resistant Staphylococcus aureus in an outbreak affecting 990 patients. Eu J Microbiol Infect Dis 13: 81-84.

Correia MP 1984. Dicionário das Plantas Úteis do Brasil e as Exóticas Cultivadas, Rio de Janeiro, Ministério da Agricultura.

Fluit AC, Jones ME, Schmitz FJ, Acar J, Gupta R, Verhoef J 2000. Antimicrobial susceptibility and frequency of occurrence of clinical blood isolates in Europe from the SENTRY Antimicrobial Surveillance Program, 1997 and 1998. Clin Infect Dis 30: 454-460.

Garibaldi RA 1992. Catheter-associated urinary tract infection. Curr Opin Infect Dis 5: 517-523.

Horan T, White JW, Jarvis WR 1986. Nosocomial infection surveillance. Mortality Weekly Report 35: 17-29.

Jawetz E, Melnik JL, Adelberg EA 2002. Microbiologia Médica. $21^{\text {a }}$ ed, Guanabara Koogan. Rio de Janeiro.

Lorenzi H 1992. Árvores brasileiras - Manual de identificação e cultivo de plantas arbóreas nativas do Brasil. Nova Odessa, São Paulo, Ed. Plantarun, pag. 230.

Menezes MV 2002. Avaliação do uso terápico de extrato de $L$. pacari na erradicação de $H$. pylori em pacientes com gastrite. In. <http://www.unifesp.br>, acesso em 7 abr 2003.

Nascimento GGF 2000. Antibacterial activity of plant extracts and phytochemicals on antibiotic-resistant bacteria. Braz J Microbiol 31: 247-256.

Oliveira CM 2002. Abrodagens biotecnológicas para a obtenção de substâncias ativas In:França SC. Farmacognosia - da planta ao medicamento. $4^{\circ}$ edição, Ed. Da UFSC, p.105120.

Reitz PR 1969. Litráceas - Flora Ilustrada Catarinense. pág. 6369.

Schaberg DR, Culver DH, Gaynes RP 1991. Major trends in the microbial etiology of nosocomial infection. Am J Med 91: $72-75$. 